\title{
ALTERNATIVAS EDUCACIONAIS: O PROVIMENTO DO ENSINO SECUNDÁRIO POR PPPS EM MINAS GERAIS ${ }^{1}$
}

\section{EDUCATIONAL ALTERNATIVES: THE PROVISION OF SECONDARY SCHOOLING THROUGH PPPS IN MINAS GERAIS}

\author{
João Victor Guedes Neto \\ Universidade Federal de Alfenas - MG \\ joaovictorguedesneto@gmail.com \\ Wesllay Carlos Ribeiro Neto \\ Universidade Federal de Alfenas - MG \\ wesllay.ribeiro@unifal-mg.edu.br
}

Submissão: $11 / 03 / 2014$

Aprovação: 05/12/2014

\section{RESUMO}

O processo histórico vigente culminou em um cenário em que agentes públicos e privados têm interagido cada vez mais para maximizar seus potenciais. As parcerias na Administração Pública são o resultado mais claro deste fenômeno e vêm se dando nos mais diversos setores da sociedade. O presente artigo busca explorar este fenômeno, analisando a utilização de parcerias público-privadas para melhorar a oferta do Ensino Médio em Minas Gerais. Para tal, realizou-se um estudo sobre a legislação vigente no país e no estado, e, comparadas com as experiências da Holanda, Estados Unidos e Colômbia, apontou-se passos que permitiram a implementação do modelo nos parâmetros estabelecidos.

Palavras-chave: Parceria público-privada. Educação. Ensino Médio.

\footnotetext{
${ }^{1}$ Os autores agradecem à FAPEMIG pelo financiamento desta pesquisa e às sugestões dos revisores que, gentil e anonimamente, auxiliaram a aumentar a qualidade deste trabalho.

Revista Economia \& Gestão - v. 14, n. 37, out./dez. 2014
} 


\begin{abstract}
The current historical process resulted in a scenario where public and private agents have been increasingly interacting to boost their potentials. Partnerships in public administration are the most relevant outcome of this phenomenon and have been happening in several sectors of society. This paper aims to explore this phenomenon, evidencing how to make use of public-private partnership to improve the supply of secondary education in Minas Gerais. In order to do that, an analysis over both the federal and state law were made, while comparing them to experiences in the Netherlands, the United States of America and Colombia, pointing out to steps that could permit the model implementing under the established parameters.
\end{abstract}

Keywords: Public-Private Partnership. Education. Secondary Education. 
Introdução

É notório que a sociedade tem passado por profundas transformações. Habermas (2003) identificou na evolução posterior à Idade Média a contínua deformação da dicotomia do público-privado, quando se torna cada vez mais difícil identificar segmentos que sejam unicamente pertencentes ao Estado ou à sociedade civil. A existência de empresas que oferecem educação e saúde aos seus trabalhadores, o comportamento do Estado que passa a tratar o cidadão como cliente, ou a individualização da família que abandona seu patriarca em busca da proteção estatal, são componentes de um fenômeno concomitante de privatização do público e publicização do privado (HABERMAS, 2003).

Reflexo claro deste processo são as parcerias na Administração Pública. Seja pela falta de recursos para a satisfação das vontades da sociedade civil, pela ineficiência da maquina pública ou puramente pelo processo histórico, tem se tornado cada vez mais constante recorrer ao setor privado e à sociedade civil para prover serviços que anteriormente eram de exclusividade do setor público. Concessões, convênios, agências reguladoras e privatizações são mecanismos comuns neste cenário.

Ainda assim, as parcerias na Administração Pública acabam sendo uma das políticas mais próximas do argumento habermasiano, por colocar lado a lado um ente público e um privado no provimento, geralmente a métodos de mercado, de algo que anteriormente não se poderia ver longe da esfera pública. A construção de estradas, a manutenção de presídios e a gestão de hospitais com oferta de serviços gratuitos são claros exemplos disto.

A educação, no entanto, praticamente não possui exemplos deste tipo de política pública no Brasil, sendo o caso de Belo Horizonte o único identificado até a conclusão deste estudo. É verdade que outras formas de parceria já foram realizadas. Casos recentes são os convênios da Prefeitura de Varginha para a abertura de vagas gratuitas em creches privadas, sem fins lucrativos, e o uso de organizações não governamentais no provimento de educação básica no município do Rio de Janeiro. O cenário deixa uma dúvida: se é inegável o rendimento elevado de diversas escolas com fins lucrativos no Exame Nacional do Ensino Médio, estabelecido pelo próprio Estado, por que não se utilizar delas para melhorar a oferta gratuita de educação no país?

$\mathrm{O}$ presente artigo visa explorar este cenário, respondendo especificamente à questão de como prover educação gratuita de qualidade por meio de parcerias públicoprivadas (PPPs). Tendo em vista a facilidade de se averiguar seu desempenho por meio de exame estabelecido pelo Estado, foi escolhido o Ensino Médio como objeto de estudo. Sendo 
este de provimento em nível estadual, a opção se deu por Minas Gerais, onde foi instituída a primeira lei de PPPs do Brasil.

Para responder à questão, utilizou-se tanto da revisão bibliográfica sobre o tema como a análise documental da legislação vigente. Cabe destacar, como fizeram Prates e Prates (2009), a diferença entre ambas: enquanto a revisão bibliográfica se dedica às fontes que já receberam certo tipo de tratamento acadêmico, a análise documental tem como corpus de pesquisa fontes sem tratamento científico ou que ainda podem ser reelaboradas de acordo com o objetivo do estudo. Neste sentido, dado o caráter recente do objeto deste trabalho, a revisão bibliográfica - realizada em cima de estudos correlatos ao tema - será complementada pela análise documental da legislação federal, estadual e municipal sobre PPPs, e do edital de concessão que versa sobre a recente iniciativa da prefeitura de Belo Horizonte.

$\mathrm{O}$ artigo foi dividido em três partes. A primeira se destina a analisar a legislação brasileira, na qual se verifica a proximidade entre as leis federal e estadual. Ainda que a validade da primeira se dê apenas no nível da União, o entendimento da mesma é importante para que se possam recomendar possíveis mudanças na legislação estadual e, ainda, servir de base para a implementação do resultado deste trabalho em outras unidades da federação. A segunda parte do trabalho analisa casos internacionais nos quais, ainda que com processos históricos e legislações diferentes da brasileira, os exemplos acabam por servir de parâmetro para a possível implementação da política em Minas Gerais. A terceira se destina à resposta final da pergunta realizada, apontando caminhos que permitam se utilizar dos potenciais do público e do privado para melhorar a oferta de educação no estado.

\section{PPPs no Brasil}

A problemática da falta de recursos públicos para investir em obras de infraestrutura e determinados serviços levou o Estado a buscar na iniciativa privada uma alternativa para sua realização. A própria Constituição Federal de 1988 indicou este caminho, como Kurachi (2007, p. 47) coloca ao afirmar que "o Estado contemporâneo surge como um Estado Regulador, Garantidor ou Pós-Intervencionista, pois esse Estado toma para si somente a tarefa de orientar e controlar o sistema econômico". A reflexo disto, segundo Aragão (2005, p. 2), iniciou-se entre as décadas de 1980 e 1990 o processo de "desestatização com a delegação da atividade à iniciativa privada" de segmentos que

podiam ter tamanho potencial de lucratividade, que a empresa privada, além de não receber qualquer suporte financeiro do Poder Público, ainda lhe pagava um valor de outorga estabelecido na licitação, remunerando-se integralmente com as tarifas pagas pelos usuários ao longo prazo de vigência da concessão ou permissão. (ARAGÃO, 2005, p. 2) 
A parceria visaria "melhores condições de prestar os serviços públicos ou de utilidade pública [...] e de viabilizar a construção de obras de infraestrutura, ou seja, de alcançar um estado de bem-estar da coletividade" (KURACHI, 2007, p. 133). O Estado contaria não somente com o suporte financeiro da iniciativa privada, como também poderia focar seus esforços na realização de atividades essenciais cujo baixo retorno financeiro não seria interessante para atrair parceiros privados. Neste cenário, a motivação para o desenvolvimento das PPPs partiria de dois pilares complementares: "o Estado por não ter condições financeiras, e a iniciativa privada porque a tarifa seria insuficiente (ou em alguns casos até inexistente) para cobrir todos os seus custos e a legítima margem de lucro do negócio" (ARAGÃO, 2005, p. 2). O modelo favoreceria o ente privado, por garantir uma oportunidade de obtenção de lucros em um percurso auxiliado pelo Estado, ao passo que a Administração Pública se beneficiaria do investimento privado que, mesmo sendo realizado parcialmente, funcionaria como um organismo de crédito, essencial em um momento de falta de liquidez de recursos públicos. Este é o fator que diferencia, como Aragão (2005) aponta, concessões e PPPs. Enquanto na primeira modalidade o investimento total é realizado pelo ente privado e financiado pelo pagamento de tarifas por parte do usuário, no segundo mecanismo existe o investimento público que pode se dar de forma parcelada, sendo realizado ao decorrer do tempo, reduzindo o ônus imediato do Estado em demandas emergenciais.

A tipificação de tal instituto veio a partir da Lei Federal $\mathrm{n}^{\circ}$ 11.079, de 30 de dezembro de 2004 (Lei das PPPs), pela qual se instituíram "normas gerais para licitação e contratação de parceria público-privada no âmbito da Administração Pública" (BRASIL, 2004). Em seu teor, e até mesmo dado às suas atualizações, percebe-se uma clara preocupação com a eficiência da empreitada, como se verifica pelo parágrafo $1^{\circ}$ do artigo $6^{\circ}$, onde se lê que "o contrato poderá prever o pagamento ao parceiro privado de remuneração variável vinculada ao seu desempenho, conforme metas e padrões de qualidade e disponibilidade definidos no contrato" (BRASIL, 2004).

A legislação brasileira, no entanto, é mais específica do que os modelos inglês e português, uma vez que as demais apontam para as PPPs como parcerias de uma forma geral, enquanto a referida lei abrange apenas "concessões patrocinadas e concessões administrativas [...] utilizando-se em maior ou menor grau a disciplina já existente das licitações públicas (Lei [Federal] $\mathrm{n}^{\circ}$ 8.666/93) e das concessões de serviços públicos (Lei [Federal] $\mathrm{n}^{\circ}$ 8.987/95)" (ARAGÃO, 2005, p. 6). 


\subsection{Modelos de PPP}

\subsubsection{Concessões patrocinadas}

O parágrafo $1^{\circ}$ do artigo $2^{\circ}$ da Lei das PPPs refere-se à "concessão de serviços públicos ou de obras públicas [...] quando envolver, adicionalmente à tarifa cobrada dos usuários contraprestação pecuniária do parceiro público ao parceiro privado" (BRASIL, 2004). Aragão (2005, p. 6) explica que a "única diferença para as concessões comuns é [...] que nessa a amortização dos investimentos privados é feita [...] integralmente pelas tarifas pagas pelos usuários, enquanto na concessão patrocinada a amortização é feita ao mesmo tempo com tarifas e verbas do próprio erário”.

Seu objetivo é "atrair investimentos privados, por meio do pagamento de adicional de tarifa pelo parceiro público, adicionalmente à tarifa dos usuários e depende de autorização legislativa nos casos em que a Administração tiver de pagar mais de $70 \%$ da remuneração do parceiro privado" (KURACHI, 2007, p. 154). A importância do projeto se dá no que tange a projetos que, de outra maneira, não poderiam ser realizados, seja pela falta de recursos do Estado, pela insuficiência das tarifas a serem pagas por seus usuários ou, em complemento a esta, a expectativa de um custo tarifário superior ao potencial de pagamento do usuário (ARAGÃO, 2005).

\subsubsection{Concessões administrativas}

O parágrafo $2^{\circ}$ do artigo $2^{\circ}$ da referida lei trata do "contrato de prestação de serviços de que a Administração Pública seja a usuária direta ou indireta, ainda que envolva execução de obra ou fornecimento e instalação de bens" (BRASIL, 2004). Neste caso, incluem-se serviços em que a tarifa não possa ou não deva ser cobrada por inviabilidade econômica, jurídica ou social, como exemplo a saúde, a educação ou serviços cujo único beneficiário é o próprio poder público (ARAGÃO, 2005).

É interessante notar ainda os três pilares identificados por Aragão (2005) na leitura feita sobre Sundfeld, cuja obra fora elaborada enquanto a legislação atual existia apenas sob a forma de projeto de lei. Como afirma, a PPP no modelo de concessão administrativa é possível quando o concessionário utiliza recursos financeiros para construir infraestrutura relevante, o Estado realiza a amortização de sua dívida em um prazo longo e a parceria não está restrita à realização de construção ou disponibilização de bens e mão de obra (SUNDFELD, 2004, apud ARAGÃO, 2005).

Seguindo esta lógica, Aragão (2005) enumera algumas das áreas nas quais seria comum ver PPPs: 
(1) serviços públicos econômicos em relação aos quais o Estado decida não cobrar tarifa alguma dos usuários (ex., rodovia em uma região muito pobre); (2) serviços públicos sociais, como a educação, a saúde e a cultura e o lazer em geral, que também podem ser prestados livremente pela iniciativa privada. [...] Por exemplo, de algumas experiências [...] de "terceirização" da administração de hospitais públicos; (3) atividades preparatórias ou de apoio ao exercício do poder de polícia. [...] Seriam os casos da hotelaria em presídios, da colocação de pardais eletrônicos em vias públicas, prestação de serviços de reboque para remoção de veículos estacionados irregularmente, etc.; (4) Atividades internas da Administração Pública, em que o próprio Estado, aí incluindo seus servidores, é o único beneficiário do serviço (ex., construção e operação de uma rede de creches ou restaurantes para os servidores públicos, construção e operação de um centro de estudos sobre a gestão administrativa para elaboração de projetos para maior eficiência do Estado, etc.). (ARAGÃO, 2005, p. 13-14)

Esta modalidade se coloca de forma mais complexa do que a simples terceirização dos serviços, uma vez que demanda investimentos do ente privado e ainda submete-se ao "Princípio da Eficiência e da necessidade de compartilhamento de riscos" (ARAGÃO, 2005, p. 15), havendo a necessidade de um cálculo específico com preço fixado à prestação concreta do serviço conveniado ao invés de um determinado valor fixado independente da qualidade do serviço realizado.

\subsection{Delimitações legais}

Destacados todos os pressupostos legais que diferenciam a lei das PPPs do entendimento geral, Aragão (2005) estabeleceu o seguinte conceito:

\footnotetext{
Contratos de delegação da construção, ampliação, reforma ou manutenção de determinada infraestrutura e da gestão da totalidade ou parte das atividades administrativas prestadas por seu intermédio, mediante remuneração de longo prazo arcada total ou parcialmente pelo Estado, fixadas em razão da quantidade ou qualidade das utilidades concretamente propiciadas pelo parceiro privado à Administração Pública ou à população. (ARAGÃO, 2005, p. 18)
}

Dentro deste escopo, é possível destacar outras delimitações legais, entre elas: a) o valor mínimo de $\mathrm{R} \$ 20$ milhões; b) valor máximo equivalente a um por cento da receita corrente líquida; c) o prazo mínimo de cinco anos e máximo de 35 anos; d) sua incidência se restringe à União; e) a demanda por licitação, precedida de consulta pública sobre o projeto, feita com critério de julgamento pela menor tarifa, menor tarifa combinada com melhor técnica, menor valor de contraprestação ou menor contraprestação combinada com a melhor técnica; f) a expressa necessidade do compartilhamento de gastos para não se violar o princípio da economicidade; g) invariavelmente divide os riscos entre os parceiros; $h$ ) e a necessidade de constituição de uma sociedade de propósito específico, ou joint venture da qual a Administração Pública pode participar desde que não seja sua controladora.

Além disso, seu artigo $2^{\circ}$ indica sete diretrizes a serem cumpridas, sendo elas: 
I - eficiência no cumprimento das missões de Estado e no emprego dos recursos da sociedade; II - respeito aos interesses e direitos dos destinatários dos serviços e dos entes privados incumbidos da sua execução; III - indelegabilidade das funções de regulação, jurisdicional, do exercício do poder de polícia e de outras atividades exclusivas do Estado; IV - responsabilidade fiscal na celebração e execução das parcerias; V - transparência dos procedimentos e das decisões; VI - repartição objetiva de riscos entre as partes; VII - sustentabilidade financeira e vantagens socioeconômicas dos projetos de parceria. (BRASIL, 2004)

Desta forma, o arcabouço legal acaba sendo devidamente delimitado, demonstrando mais uma vez clara diferenciação quando comparado aos modelos inglês e português, entre outros. A diferença importa ao passo que, revisando a literatura estrangeira, é possível perceber a impossibilidade da importação direta de procedimentos, cabendo sempre ao pesquisador o cuidado de se adaptar também o entendimento sobre as diferenças legais entre cada modelo.

\subsection{Problemáticas}

Uma vez que o mecanismo garante a realização imediata de atividades que só se fazem possíveis por meio de um investimento de médio e longo prazo, corre-se o risco de que o preceito seja utilizado para ganhos políticos imediatistas em detrimento da austeridade orçamentária futura, comprometendo parcialmente o orçamento da União dado não à real necessidade do Estado, mas às pressões políticas e à oportunidade de perpetuação eleitoral do partido governista. A Lei de Responsabilidade Fiscal (Lei Complementar $n^{\circ}$ 101/00) atua nesta problemática uma vez que "estabelece limites globais para a dívida consolidada e para as operações de crédito dos entes da federação" (ARAGÃO, 2005, p. 22). Além desta, o artigo 22 da própria lei das PPPs limita "os gastos com parcerias público-privadas a um por cento da receita corrente líquida". Tal receita inclui, entre outros, aquilo que advém de tributos, contribuições, patrimônios, indústria, agropecuária, serviços e transferências correntes (ARAGÃO, 2005).

Também com cunho político, a média e longa duração das PPPs acaba por gerar mais um risco, sendo este a possibilidade de inadimplência do Estado. Seja pela real falta de recursos ou pela mudança do grupo político no governo - e assim dos interesses em voga surge a possibilidade de que o Estado não honre com seu compromisso, gerando um prejuízo considerável para o parceiro privado. Como cita Aragão (2005), o artigo $11^{\circ}$, inciso III, da lei das PPPs oferece a possibilidade do uso da Lei de Arbitragem para resolução de disputas; além do artigo $8^{\circ}$ que impõe garantias de pagamento por parte da Administração Pública, incluindo 
I - vinculação de receitas, observado o disposto no inciso IV do art. 167 da Constituição Federal; II - instituição ou utilização de fundos especiais previstos em lei; III - contratação de seguro-garantia com as companhias seguradoras que não sejam controladas pelo Poder Público; IV - garantia prestada por organismos internacionais ou instituições financeiras que não sejam controladas pelo Poder Público; V - garantias prestadas por fundo garantidor ou empresa estatal criada para essa finalidade; VI - outros mecanismos admitidos em lei. (BRASIL, 2004)

O estudo realizado por Peci et al. (2012, p. 83) auxilia a identificar outras problemáticas uma vez que levanta "uma longa lista de fatores que possam incentivar ou dificultar a adoção dessa modalidade de execução de serviços públicos”. Cabe apontar tais fatores, mesmo que brevemente, em complementação ao que fora apresentado neste trabalho até o momento. São eles: a) modelagem de contratos, na qual dada a sua natural incompletude, existe possibilidade de maior ou menor ganho para o ente privado; b) marco regulatório, em que o maior desenvolvimento institucional no campo da Nova Administração Pública facilita a execução das PPPs; c) mecanismos de sanção e compliance, onde a capacidade de monitorar e punir, por parte do Estado, garante a maior efetividade no processo; d) garantias, como já explanado; e) planejamento, facilitando o estabelecimento e manutenção da PPP, até mesmo incluindo seu relacionamento com a sociedade civil e o setor privado; f) expertise do órgão de coordenação e apoio, essencial para o desenvolvimento dos institutos reguladores do processo; g) corrupção e aspectos éticos, nos quais a fraude realizada no único momento de competição, a licitação, já tende a comprometer todo o processo, além, é claro, de toda a gestão do processo; h) transparência e acesso à informação, para que haja explicidade nos ganhos de eficiência e economicidade; i) clareza conceitual, principalmente onde há aversão, por parte da opinião pública, às privatizações; j) resistência dos servidores e da sociedade, sendo prejudicada principalmente quando havia gestão pública do objeto da parceria; k) apoio político, a fim e garantir credibilidade e legitimidade; e 1) situação econômica do setor público, para a qual o baixo orçamento colabora para a adoção desta política (PECI et al., 2012).

\subsection{PPPs em Minas Gerais}

Em sentido semelhante à justificativa encontrada sobre a introdução das PPPs no Brasil e no mundo (ARAGÃO, 2005; PECI et al., 2012), Peci et al. (2012, p. 81) identificaram no caso de Minas Gerais "uma tentativa do Estado de, em face da escassez de recursos, viabilizar a execução de obras custosas, utilizando-se do capital privado e da partilha dos riscos inerentes ao empreendimento". 
É interessante notar que a legislação referente às PPPs em Minas Gerais originouse antes mesmo da lei federal, sendo sancionada em 16 de dezembro de 2003, enquanto a outra, como já citado, passou a vigorar um ano após, em 30 de dezembro de 2004 (MINAS GERAIS, 2003; BRASIL, 2004). Segundo a lei mineira, bem similar à nacional,

\begin{abstract}
as parcerias público-privadas [...] constituem contratos de colaboração entre o Estado e o particular por meio dos quais, nos termos estabelecidos em cada caso, o ente privado participa da implantação e do desenvolvimento de obra, serviço ou empreendimento público, bem como da exploração e da gestão das atividades deles decorrentes, cabendo-lhe contribuir com recursos financeiros, materiais e humanos e sendo remunerado segundo o seu desempenho na execução das atividades contratadas [...] [podendo] ser desenvolvidas nas seguintes áreas: I - educação, saúde e assistência social; II - transportes públicos; III - saneamento básico; IV segurança, sistema penitenciário, defesa e justiça; $\mathrm{V}$ - ciência, pesquisa e tecnologia; VI - agronegócio, especialmente na agricultura irrigada e na agroindustrialização; VII - outras áreas públicas de interesse social ou econômico. (MINAS GERAIS, 2003)
\end{abstract}

Entre as delimitações impostas, percebe-se mais uma vez um viés similar à legislação federal, onde existe a obrigatoriedade de manutenção e exploração do ente privado "por, no mínimo, quarenta e oito meses"; o mínimo de cinco anos de concessão ou permissão e o investimento de $\mathrm{R} \$ 20.000 .000,00$; a impossibilidade de abranger poder de polícia ou quaisquer atividades indelegáveis, além de "atividade de ensino que envolva processo pedagógico". No mais, institui-se a obrigatoriedade da elaboração anual de um Plano Estadual de Parcerias Público-Privadas por parte o Conselho Gestor de Parcerias Público-Privadas, da execução de licitação e do estabelecimento de garantia, entre outros mecanismos consonantes com a legislação federal instituída posteriormente (MINAS GERAIS, 2003).

A partir dos dados disponibilizados pela Unidade PPP (MINAS GERAIS, 2013), "responsável por coordenar e apoiar a realização de projetos no âmbito do Programa Estadual de Parcerias Público Privadas [...] [e] disseminar a metodologia própria de contratos de PPPs" (PECI et al., 2012), verifica-se que o estado de Minas Gerais possui atualmente quinze projetos em andamento e quatro contratos de parceria público-privada já celebrados, sendo eles a) a Rodovia MG-050, compreendendo "a exploração da Rodovia MG-050, no trecho entroncamento BR-262 (Juatuba) - Itaúna - Divinópolis - Formiga - Piumhi - Passos - São Sebastião do Paraíso, no trecho Entre MG 050/Entre BR-265 da BR 49115 do km 0,0 ao km 4,65 e no trecho São Sebastião do Paraíso - Divisa MG/SP da Rodovia BR 265”; b) o Complexo Penal, incluindo "a disponibilização de 3000 vagas prisionais, divididas em cinco unidades prisionais, sendo três para o regime fechado e duas para o regime aberto. Além disso, é prevista a construção de uma unidade de administração central do Complexo Penal"; c) a Unidade de Atendimento Integrado (UAI), abrangendo sua "implantação, gestão, 
operação e manutenção [...] em Betim, Governador Valadares, Juiz de Fora, Montes Claros, Uberlândia e Varginha"; e d) o Estádio Governador Magalhães Pinto (Mineirão) (MINAS GERAIS, 2013).

A problemática política e o desejo por reduzir custos acabaram por estimular o Governo de Minas Gerais a promover dois institutos de interação com a sociedade civil e o setor privado. O primeiro deles, o Processo de Consulta Pública, "trata-se de instrumento que visa obter opiniões da população em relação às minutas de edital e de contrato dos projetos". O Procedimento de Manifestação de Interesse, por sua vez, "é o instrumento em que os potenciais participantes do processo licitatório podem encaminhar sugestões para a elaboração dos futuros projetos do governo" (PECI et al., 2012, p. 86).

\section{PPPs na educação}

A motivação para adotar o modelo de PPP na educação (PPPE) surgiu ainda na década de 1980 a partir de gestores públicos que passaram a reconhecer que os "métodos tradicionais de financiamento e gestão não foram capazes de oferecer educação básica de qualidade para todas as crianças" (GENEVOIS, 2008, p. 6) (tradução nossa). A problemática do ensino básico acaba se estendendo também para o secundário não só por possuir um dinamismo similar mas também pois, como Caillods (2001, apud GENEVOIS, 2008, p. 2) afirmou, "quaisquer recursos adicionais que o Estado seja capaz de mobilizar não necessariamente estarão disponíveis para a educação secundária, já que para atingir a educação primária universal ainda é requerida uma grande quantidade de recursos" (tradução nossa). O uso do novo modelo poderia resultar em uma soma de esforços para questões como "provisão financeira, desenvolvimento pedagógico, desenvolvimento de recursos humanos, oferta do serviço, infraestrutura, gerenciamento de construções, entre outros" (GENEVOIS, 2008, p. 6) (tradução nossa). Para Patrinos (2006, p. 1), o ganho estaria no potencial de "corrigir as ineficiências na oferta pública de serviços educacionais", incluindo benefícios como "efetividade frente ao custo, equidade, desempenho e economia de custos" (tradução nossa)

É importante notar a diferente conotação que uma PPPE possui em relação a outros métodos de financiamento público da provisão privada de educação bem como existe no Brasil, por exemplo, a partir do Programa Universidade Para Todos. O conceito adotado neste trabalho segue àquele apontado Patrinos (2006, p. 2) como "o instrumento específico de contratação [...] [no qual] contratação se refere ao processo onde o governo delega a serviços de educação ou relacionados à educação, de quantidade e qualidade definidos, por um preço acordado, com provedor e duração específicos" (tradução nossa). Neste modelo específico de Revista Economia \& Gestão - v. 14, n. 37, out./dez. 2014 
escolas financiadas pelo setor público mas geridas pelo setor privado, como Patrinos et al. (2009) colocam, cria-se a possibilidade de aumentar tanto sua qualidade quanto eficiência, dado à redução de barreiras burocráticas e pressões sindicais, e maior proximidade dos órgãos decisórios e seu público alvo.

Neste escopo, cabe identificarem algumas experiências que giram em torno do mesmo princípio, ainda que divergindo em determinados aspectos das delimitações legais do Brasil. São elas o modelo educacional holandês, as Education Management Organizations nos Estados Unidos e o programa Colegios en Concesion na Colômbia.

\subsection{Holanda}

Um dos modelos mais antigos de estímulo à livre iniciativa na educação, o sistema holandês garantiu, a partir de sua Constituição Federal de 1848, a "indivíduos e organizações o direito de estabelecer escolas independentes sem prévia aprovação do governo ou da igreja", onde os princípios de liberdade de Convicção, Organização e Estabelecimento de Escolas davam plenas liberdades em relação a questões como os modelos pedagógico e administrativo a serem adotados. O financiamento estatal, previamente disponível apenas para escolas públicas, passou a ser ofertado também para as independentes a partir de 1917 (JUSTESEN, 2002, p. 16-24).

Ainda que a regulamentação tenha crescido com o tempo, permanece consideravelmente liberal em face das outras nações europeias. Para receber financiamento estatal, a escola precisa ser aprovada pelo Ministério da Educação e atender uma gama de requerimentos, bem como a matrícula mínima de 333 alunos em cidades e 200 em áreas rurais. Desta forma, acaba por forçar que o estabelecimento se dedique a atender a demanda dos pais da região escolhida. Em 1998, 76\% dos estudantes secundários estavam matriculados em escolas independentes, em detrimento daquelas geridas pelo Estado. No mesmo ano, o custo marginal médio por aluno por ano era de 5304 dólares. A distribuição do recurso, no entanto, não é igual para todas as escolas, recebendo adicionais financeiros aquelas cujas famílias atendidas possuam menores condições financeiras, gerando um estímulo maior para o estabelecimento de escolas em regiões mais carentes (JUSTESEN, 2002).

\subsection{Estados Unidos}

O modelo educacional americano é complexo uma vez que, dado a sua descentralização, possui mais de 15.000 distritos com grande autonomia sobre o provimento de educação. Ainda que políticas nacionais existam, bem como a que cria as Education Management Organizations (EMO), existe grande liberdade no modelo a ser adotado por cada Revista Economia \& Gestão - v. 14, n. 37, out./dez. 2014 
distrito, inclusive na definição do que será entregue ao setor privado e o que permanecerá sob a tutela do Estado. Interessante notar que a EMO pode ser composta com ou sem fins lucrativos, tendo ainda a possibilidade de administrar mais de uma escola ao mesmo tempo (FITZ; BEERS, 2002).

A forma principal de interação público-privado das mesmas se dá sob contratos em que a EMO assume a responsabilidade de gestão de uma escola pública que, geralmente, encontrava-se em situação precária. O contrato é sempre vinculado a algo comensurável, mas ainda assim pode variar, englobando, por exemplo, uma melhora no rendimento dos alunos ou a redução dos custos da instituição. Caso o objetivo não seja cumprido, garante-se o direito ao distrito escolar de cancelar o contrato com a EMO, retomando o controle sobre a escola.

O valor, acordado entre as partes tende a ser calculado com base no número de alunos atendidos, sendo o lucro destinado à remuneração da EMO (FITZ; BEERS, 2002). Neste aspecto, para evitar que o ente privado reduza a qualidade do ensino a fim de garantir maior retorno financeiro, cabe ao Estado definir regras que forcem ao bom rendimento do empreendimento. Como reporta Patrinos et al. (2009), no ano escolar de 2005-2006, 521 escolas distribuídas em 29 estados operavam sob a gestão de uma EMO.

\subsection{Colômbia}

Em 1999 o governo municipal de Bogotá adotou o programa Colegios en Concesión no qual firmou contrato de 15 anos com o setor privado concedendo a gestão de 25 escolas recém-construídas que abrangeriam por volta de 25.000 estudantes das regiões mais pobres da cidade (BARRERA-OSORIO; MALDONADO; RODRIGUEZ, 2012). O mesmo incluiria

\footnotetext{
(i) autonomia no gerenciamento da escola, (ii) infraestrutura estatal, (iii) valor do contrato estimado com base no custo marginal aproximado por aluno e o número de estudantes servidos [em torno de 500 dólares por aluno ao ano], (iv) especificação de níveis educacionais disponíveis [...], e (v) a inexistência de contrato laboral entre o Estado e o pessoal administrativo e pedagógico partícipes do contrato. Em complemento, o contrato deveria especificar a qualidade do serviço a ser prestado e o contínuo ingresso de um número estipulado de alunos. (PATRINOS, 2006, p. 16; tradução nossa)
}

Melhoras moderadas foram encontradas ao decorrer do programa, incluindo a melhora no desempenho em provas de matemática $(2,4 \%)$ e línguas $(4 \%)$, além da elevação no índice de retenção $(1,7 \%)$ que, embora pequena, acabou por elevar também o mesmo nas escolas vizinhas (BARRERO-OSORIO, 2012; PATRINOS, 2006). 


\section{Implementação em Minas Gerais}

A baixa eficiência do investimento público realizado na educação é perceptível quando se analisa as disparidades entre os resultados das escolas públicas e privadas no Exame Nacional do Ensino Médio (ENEM). Além disso, a falta de recursos para desenvolver o sistema público, como visto anteriormente em nível global, auxilia a deteriorar o cenário. O fenômeno se agrava ao perceber que o próprio Estado assume sua ineficiência ao instituir uma política de cotas universitárias para alunos oriundos da rede pública. Estas problemáticas levam à necessidade de se buscar alternativas administrativas no provimento educacional, bem como é o caso da PPP.

É verdade que a ideia de PPPEs não é inédita no Brasil. Apesar de nova, a experiência está sendo realizada pela Prefeitura Municipal de Belo Horizonte desde o lançamento do Edital de Concessão n 01/2012 que toma por base o modelo de Concessão Administrativa prevista pela Lei Municipal $\mathrm{n}^{\circ}$ 10.377, de nove de janeiro de 2012. A diferença desta para o proposto neste trabalho reside no objeto licitado, uma vez que o projeto municipal, dado à normal federal sobre a distribuição de responsabilidades sobre a educação, se restringe à "realização de obras e serviços de engenharia e prestação de serviços de apoio, não pedagógicos, a Unidades de Ensino da Rede Municipal de Educação Básica" (BELO HORIZONTE, 2012). O presente trabalho, por sua vez, destina-se a estudar o possível processo licitatório da esfera estadual mineira incidindo sobre as unidades prestadoras de Ensino Médio.

A problemática inicial é que a implementação de PPPEs em Minas Gerais, ainda que permitida pela legislação federal, demandaria a correção de uma contradição legal presente na lei estadual de PPPs. Enquanto seu artigo $5^{\circ}$, parágrafo $1^{\circ}$, inciso I, garante o desenvolvimento de atividades relacionadas à educação, seu artigo $6^{\circ}$, inciso IV, veda "a delegação a ente privado [...] atividade de ensino que envolva processo pedagógico" (MINAS GERAIS, 2003). Ao consultar o Dicionário Michaelis, por exemplo, percebe-se a similaridade dos conceitos de pedagogia e educação. O primeiro se trata do "estudo teórico ou prático das questões da educação" ou da "arte de instruir, ensinar ou educar as crianças"; o segundo é o "ato ou efeito de educar" ou o "aperfeiçoamento das faculdades físicas, intelectuais e morais do ser humano". Vista a contradição, o esforço inicial do legislador interessado deverá ser voltado a reformar a legislação estadual para evitar problemas jurídicos.

Ainda que objeto distinto, é interessante notar a preocupação da Prefeitura Municipal de Belo Horizonte ao especificar em seu edital a inclusão, apenas, de serviços não pedagógicos. É verdade que não há clara especificação do que estes seriam, mas a delimitação 
das atribuições delegadas ao ente privado acaba por corroborar com a conclusão tirada do parágrafo anterior. Inclui-se no edital:

(i) a execução de obras de construção nas unidades de ensino [...]; (ii) a aquisição, operação, manutenção e reposição de mobiliários e equipamentos necessários para o funcionamento das unidades de ensino; (iii) a gestão, conservação, manutenção e eventual compra dos bens vinculados [...]; (iv) a oferta e gestão dos serviços de higiene e limpeza, lavanderia e rouparia, serviços administrativos, utilidades e energia, segurança e quaisquer outros necessários à plena execução dos serviços previstos no edital, contrato e respectivos anexos da presente concessão. (BELO HORIZONTE, 2012)

A problemática gerada pela restrição é a impossibilidade de se utilizar determinados métodos pedagógicos, como o de escolas privadas com altos índices de aprovação nos vestibulares, ENEM e mercado de trabalho, em benefício do modelo público, cujo rendimento - seja pela falta de recursos ou pela deficiência pedagógica - é notadamente inferior. Perde-se pluralidade e o potencial de levar ao aluno da rede pública os avanços gerados pela competição da iniciativa privada. Neste sentido, a reforma legal poderia permitir ao gestor público uma ferramenta a mais na formulação de políticas públicas que garantam bem estar e desenvolvimento humano à população.

A experiência internacional motiva a utilizar-se deste modelo, bem como fora feito na Colômbia, de maneira experimental, selecionando-se para tal, ao exemplo americano, escolas cujo rendimento seja inferior à média estadual e, evitando-se a problemática política sugerida por Peci et al. (2012), em regiões onde o diálogo político não ofereça riscos, tanto nas esferas do governo como da sociedade civil. Cabe ao gestor público perceber, também por meio do instituto da Consulta Pública, as cidades e escolas com maior potencialidade de acerto em uma iniciativa experimental. Lembra-se ainda que tal processo político, quanto mais aprofundado for, terá o potencial mais elevado de desenvolver um formato contratual mais adequado, apresentando clareza conceitual, um marco regulatório verificável e cumprível, e objetivos claramente relevantes dado o investimento a ser realizado.

O custeamento da parceria deve ser analisado com cautela. Trata-se de serviço em que há cobrança de tarifa é vedada pelo artigo 206, inciso IV, da Constituição Federal; além de se dar em condições nas quais o usuário provavelmente não teria condições de pagá-la. Assim, o Estado permaneceria custeando a totalidade das despesas do serviço, no que configuraria a PPP por Concessão Administrativa, caso aplicada a legislação federal. O piso legal de $\mathrm{R} \$ 20.000 .000,00$ implica um alto investimento que possivelmente não seria realizado caso a instituição estivesse sob o controle estatal. Isto leva a três alternativas: 1. Um contrato de longa duração no qual o investimento poderia ser diluído nos anos de serviço prestado, 
equivalendo ao que seria gasto pelo Estado; 2. A construção da escola por parte do ente privado, tratando-se de oportunidade no caso de déficit educacional em determinada região, enquanto anularia a possibilidade de melhorar a prestação de serviço em escola preexistente; ou 3. A extensão da parceria a mais de uma escola - neste caso, a criação de pessoa jurídica específica para a realização do serviço poderia se espelhar no modelo americano de Education Management Organizations.

O pagamento seriado a ser realizado pelo Estado segue, como indicado, o cumprimento daquilo que versa o contrato. Tendo em consideração o objetivo de melhorar a qualidade do serviço prestado, não há estimador mais eficiente do que o resultado obtido por seus alunos concluintes no ENEM. Além disso, como as análises sobre o caso colombiano demonstram, não se pode desconsiderar a importância do índice de retenção escolar, uma vez que se relaciona diretamente com o grau de satisfação tanto do aluno como de sua família. Assim sendo, o período mínimo de cinco anos é providencial, pois garante que o ente privado terá formado ao menos três turmas ao final do prazo mínimo, considerando-se os três anos do Ensino Médio. Ainda que o ideal seja a realização de um contrato com duração superior, entende-se que até mesmo este prazo já seria suficiente para perceber melhoras.

Além disso, bem como é realizado nos demais países analisados e a legislação local permite, a não obtenção dos índices de desempenho mínimos registrados pelo contrato garantiriam ao ente público a possibilidade de quebrar o contrato, sem prejuízo para o mesmo que poderia optar ou pelo retorno da gestão pública ou por um novo processo licitatório. Neste novo processo, bem como poderia ter sido realizado no primeiro, existiria o potencial de, dentro de pisos e tetos previamente definidos, escolher a empresa cuja oferta fosse mais compatível com as disponibilidades financeiras e os objetivos educacionais do Estado.

Por fim, a positividade da iniciativa poderia ser justificada pelo potencial de melhor previsão dos gastos por parte do Estado. Uma vez que seu investimento apenas variará de acordo com o desempenho do parceiro privado, seu orçamento não estará à mercê da variabilidade mercadológica. É verdade que o argumento pode resultar em perda para o Estado, caso o nível de preços caia após o estabelecimento do contrato. Ainda assim, a previsibilidade orçamentária representa um ganho para o gestor.

\section{Considerações finais}

Percebe-se pelo trabalho que a insuficiência de recursos públicos atrelados a sua incapacidade de prover determinados serviços com eficiência faz com que este busque alternativas para atender às demandas da sociedade civil. A PPP foi um dos mecanismos criados para suprir tal carência. Por meio da mesma é possível interagir com o setor privado, Revista Economia \& Gestão - v. 14, n. 37, out./dez. 2014 
de forma a se utilizar de sua eficiência e recursos, ao passo que se mantém os controles estatal e social sobre a oferta em questão.

A utilização deste instrumento para o provimento de educação não é nova, tendo origem na Holanda há mais de um século, e amplamente utilizada nos Estados Unidos. É verdade que a realidade de ambos os países é diferente da brasileira, mas o exemplo colombiano acaba por demonstrar que esta alternativa não está tão distante quanto poderia parecer. É necessário, no entanto, uma adaptação ao modelo brasileiro, que conta com sólidas instituições educacionais ao mesmo tempo em que enfrenta graves problemáticas estruturais. O pioneirismo de Belo Horizonte, neste sentido, é fundamental para motivar gestores a conhecer esta possibilidade.

Em vista do potencial, reformar a legislação não deve ser um impeditivo para que gestores públicos se aproveitem deste modelo que vem demonstrando sucesso em diversas localidades do mundo. Cabe, no entanto, cautela principalmente na elaboração dos contratos e, essencialmente, no contato com o público - este, agente essencial em qualquer iniciativa do Estado.

Espera-se ao final deste trabalho ter despertado a atenção de agentes públicos e acadêmicos, estimulando o debate sobre alternativas no provimento da educação no Brasil e, ainda, na aproximação de teoria e prática no estudo da Administração Pública. 


\section{REFERÊNCIAS}

ARAGÃO, A. As parcerias público-privadas no direito positivo brasileiro. Revista Eletrônica de Direito Administrativo Econômico, Salvador, n. 2, p. 1-41, 2005.

BARRERA-OSORIO, F.; MALDONADO, D.; RODRIGUEZ, C. Calidad de la educación básica y media en Colombia: diagnóstico y propuestas. Serie Documentos de Trabajo, n. 126. Rosário: Universidad del Rosario, 2012.

BELO HORIZONTE. Edital de Concessão 01/2012. Disponível em <http://portalpbh.pbh.gov.br/pbh/ecp/files.do?evento=download\&urlArqPlc=Edital_PPP_edu cacao_edu.pdf>. Acesso em: 29 nov. 2013.

BRASIL. Lei $\mathbf{n}^{\mathbf{0}}$ 11.079, de 30 de dezembro de 2004. Disponível em: <http://www.planalto.gov.br/ccivil_03/_ato2004-2006/2004/lei/111079.htm>. Acesso em: 03 nov. 2013.

CAILLODS, F. Financing secondary education in developing countries: strategies for sustainable growth. Paris: UNESCO Publishing, 2001.

FITZ, J.; BEERS, B. Education Management Organizations and the Privatization of Public Education: a Cross-National Comparison of the USA and Britain. Comparative Education, Glasgow, v. 38, n. 2, p. 137-154, 2002.

GENEVOIS, I. Can and Should Public Private Partnerships Play a Role in Education? In: Directions in Educational Planning: Symposium to Honour the Work of Françoise Caillods. Paris: International Institute for Educational Planning, 2008.

HABERMAS, J. Mudança estrutural da esfera pública: investigações quanto a uma categoria da sociedade burguesa. Rio de Janeiro: Tempo Brasileiro, 2003.

JUSTESEN, M. Learning from Europe: the Dutch and Danish School Systems. Londres: Adam Smith Institute, 2002.

KURACHI, N. A parceria público-privada como instrumento efetivo do desenvolvimento econômico e social. 2007. 204p. Dissertação (Mestrado em Direito) - Universidade de Marília, Marília, 2007.

MINAS GERAIS. Lei $\mathbf{n}^{\mathbf{0}} \mathbf{1 4 . 8 6 8}$, de 16 de dezembro de 2003. Disponível em: <http://www.ipsm.mg.gov.br/arquivos/legislacoes/legislacao/leis/lei_14868.pdf>. Acesso em: 05 nov. 2003. 
MINAS GERAIS. Portal da Unidade PPP. Disponível em: <http://www.ppp.mg.gov.br>. Acesso em: 05 nov. 2013.

PATRINOS, H.; BARRERA-OSORIO, F.; GUÁQUETA, J. The Role and Impact of PublicPrivate Partnerships in Education. Washington: The World Bank, 2009.

PATRINOS, H. Public-Private Partnerships: Contracting Education in Latin America. World Bank Working Paper. Washington: The World Bank, 2006.

PRATES, J.; PRATES, F. Problematizando o uso da técnica de Análise Documental no Serviço Social e no Direito. Sociedade em Debate, Pelotas, v. 15, n. 2, p. 111-125, 2009.

PECI, A. et al. Parcerias Público-Privadas em Minas Gerais: racionalidade técnica versus política. Contabilidade, Gestão e Governança, Brasília, v. 15, n. 1, p. 80-95, 2012.

SUNDFELD, A. Projetos de Lei de Parcerias Público-Privadas: análise e sugestões, mimeo, 2004. 